\title{
Not only pulmonary rehabilitation for critically ill patients with COVID-19
}

\author{
Anna Estraneo ${ }^{1,2}\left(\right.$ Marco Ciapetti $^{3} \cdot$ Carlo Gaudiosi $^{4} \cdot$ Antonello Grippo $^{1,5}(0)$
}

Received: 26 April 2020 / Revised: 8 July 2020 / Accepted: 10 July 2020 / Published online: 16 July 2020

c) Springer-Verlag GmbH Germany, part of Springer Nature 2020

\section{Dear Sirs,}

From the start of the COVID-19 outbreak, an increasing amount of scientific literature focused on epidemiology, pathophysiology and, especially, on treatment in the acute phase of patients with severe acute respiratory syndrome due to coronavirus 2 (SARS-CoV-2) infection [1]. Pulmonary rehabilitation is recommended to reduce symptoms of respiratory failure and distress and to restore pre-morbid functionality in the acute [2] and post-acute phase of COVID-19 [3]. Tailored respiratory rehabilitation in severe acute respiratory distress aims at mechanical ventilation weaning, and improving ventilation and oxygenation [4].

Although the lung is the principal target of coronavirus infection, clinical signs of central (i.e. dizziness, headache and/or impaired consciousness) and/or peripheral nervous system (i.e. taste and/or smell impairment) involvement have been reported especially in patients requiring mechanical ventilation [5]. Dissemination of SARS-CoV-2 in the central nervous system might occur via systemic circulation or the cribriform plate of the ethmoid bone [6], as reported in the cases of SARS-CoV in the past [7]. Pathogenesis of peripheral nerve involvement remains poorly investigated.

In mechanically ventilated patients, unavoidable immobility, systemic inflammatory response syndrome, and use of sedative drugs often determine secondary neuromuscular impairment, characterized by generalized weakness (intensive care unit-acquired weakness, ICU-AW) [8]. ICU-AW

\footnotetext{
Anna Estraneo

aestraneo@gmail.com

IRCCS Fondazione Don Carlo Gnocchi, Florence, Italy

2 Neurology Unit, SM Della Pietà General Hospital, Nola, Italy

3 Cure Intensive del Trauma E Delle Gravi Insufficienze D'organo, AOU Careggi, Florence, Italy

4 COVID Unit, General Hospital, Boscotrecase, Italy

5 SODc Neurofisiopatologia, AOU Careggi, Florence, Italy
}

can be ascribed to sensory-motor axonal polyneuropathy, primary myopathy, or muscle disuse atrophy, alone or in combination, due to critical illness [8]. The diagnosis of ICU-AW is based on clinical assessment of strength on all limbs, for instance, using the Medical Research Council (MRC) scale [9]. The volitional motor activity, however, could be not easily assessed in critical patients admitted to ICU because of comatose state or effect of sedative drugs [10]. Therefore, "non-volitional" tests, such as neurophysiological evaluation, can provide useful clues to the diagnosis of peripheral nerve and/or muscular impairment [11].

In this pilot observational study, we investigated occurrence of combined critical illness polyneuropathy and myopathy (CIPNM), as one of the leading causes of the ICUAW in a sample of nine mechanically ventilated COVID-19 patients consecutively admitted to ICU of the Careggi Hospital in Florence, Italy, from 23 March 2020 to 10 April 2020. Eight patients were not cooperative, and one was awake. We evaluated: (1) muscle power grading motor responses according to MRC scale (in non-cooperative patients, the motor responses to nociceptive stimuli were considered); (2) nerve conduction velocities, compound muscle action potentials (CMAP) and sensory nerve action potentials (SNAP) of six motor and four sensitive nerves in bilateral upper and lower limbs; (3) spontaneous muscle activity in bilateral tibialis anterior and biceps by needle EMG. The presence of CIPNM was defined by very low amplitude of CMAP and/or SNAP on neurophysiological evaluation with normal or mildly reduced nerve conduction velocities, associated with myopathic features on needle electromyography [12]. Data about pre-existing comorbidities, such as diabetes and hypertension, were also collected.

All patients achieved a low MRC score and showed severely reduced or absent osteotendinous reflexes on bilateral upper and lower limbs. Four patients had diagnosis of CIPNM at neurophysiological evaluation, and 3 of the remaining five patients presented neurophysiological 
Table 1 Demographic, anamnestic and clinical findings in patients with (+) or without (-) critical illness polyneuromyopathy

\begin{tabular}{llll}
\hline & Total sample & CIPNM+ & CIPNM- \\
\hline$N$ & 9 & 4 & 5 \\
Mean age in years (range) & $69(57-80)$ & $64(57-72)$ & $71(60-80)$ \\
Sex F/M $(n)$ & $1 / 8$ & $1 / 3$ & $0 / 5$ \\
$\begin{array}{l}\text { Mean time from ICU } \\
\text { admission in days }\end{array}$ & $28(18-30)$ & $29(20-30)$ & $25(18-25)$ \\
$\quad$ range) & & & \\
Previous history of comorbidities & & \\
$\begin{array}{l}\text { Diabetes }(n, \%) \\
\text { COPD }(n, \%)\end{array}$ & $2,22 \%$ & $1,25 \%$ & $1,20 \%$ \\
$\quad$ Hypertension $(n, \%)$ & $3,10 \%$ & $1,20 \%$ & 0 \\
MRCs mean (range) & $21(12-40)$ & $15(12-24)$ & $30(12-40)$ \\
\hline
\end{tabular}

Descriptive data are reported as mean, range and percentages referred to the whole number of patients with or without Intensive care unitacquired weakness

CIPNM combined critical illness polyneuropathy and myopathy, $F$ female, $M$ male, $I C U$ intensive care unit, $C O P D$ chronic obstructive pulmonary disease, MRCs Medical Research Council sum score

findings consistent with common peroneal nerve compression (Table 1).

The present findings suggest that in critically ill patients affected by COVID-19, functional motor deficits should be searched for. Indeed, such neuromuscular complications have been found to negatively affect weaning from mechanical ventilation long-term outcome [13] and increase in-hospital mortality [14] of critical patients. As most patients in ICU are not cooperative, clinical evaluation of muscle power is hampered. On this basis, early recognition of neuromuscular impairment by multimodal neurophysiological evaluation could help clinicians to plan an appropriate (not only pulmonary) neuromotor rehabilitation (e.g. by early passive limbs mobilization and posture changes) for improving respiratory function and clinical outcome [15]. Further studies are warranted for ascertaining whether the involvement of peripheral nerves and muscular tissue is indeed secondary to critically illness or might be directly correlated to SARSCoV-2 infection.

\section{Data availability statement}

The data that support the findings of this study are available from the corresponding author $[\mathrm{AE}]$, upon reasonable request.

Acknowledgements The authors would like to thank Dr. Andrea Ammannati, Dr. Cristina Boccardi, Dr. Cesarina Cossu and Dr. Simone Troiano who participated in the study for their help with neurophysiological data collection.
Funding This research did not receive any specific grant from funding agencies in the public, commercial, or not-for-profit sectors.

\section{Compliance with ethical standards}

Conflicts of interest On behalf of all authors, the corresponding author states that there is no conflict of interest.

Ethical standards This study was approved by the Ethical standards Committee of the AOU Careggi of Florence, Italy, and performed according to the ethical standards of Declaration of Helsinki (1964) and its later amendments. The surrogate decision-makers of the patients enrolled in the study provided their written informed consent.

\section{References}

1. Huang C, Wang Y, Li X et al (2020) Clinical features of patients infected with 2019 novel coronavirus in Wuhan China. Lancet 395:497-506. https://doi.org/10.1016/S0140-6736(20)30183-5

2. Chengrui Z, Yunhai W, Hongyan L et al (2020) Early pulmonary rehabilitation for SARS-CoV-2 pneumonia: experience from an intensive care unit outside of the Hubei province in China. Heart Lung. https://doi.org/10.1016/j.hrtlng.2020.04.007(Epub ahead of print)

3. Grasselli G, Zangrillo A, Zanella A, The COVID-19 Lombardy ICU Network et al (2020) Baseline characteristics and outcomes of 1591 patients infected with SARS-CoV-2 admitted to ICUs of the Lombardy Region, Italy. JAMA. https://doi.org/10.1001/ jama.2020.5394(Epub ahead of print)

4. Wang TJ, Chau B, Lui M, Lam G-T, Lin N, Humbert S (2020) PM\&R and Pulmonary Rehabilitation for COVID-19. Am J Phys Med Rehabil. https://doi.org/10.1097/PHM.0000000000001505

5. Mao L, Jin H, Wang M et al (2020) Neurologic manifestations of hospitalized patients with coronavirus disease 2019 in Wuhan, China. JAMA Neurol. https://doi.org/10.1001/jamaneurol .2020.1127(Epub ahead of print)

6. Am B, Khaleeq A, Ali U, Syeda H (2020) Evidence of the COVID-19 virus targeting the CNS: tissue distribution, hostvirus interaction, and proposed neurotropic mechanisms. ACS Chem Neurosci 11:995-998. https://doi.org/10.1021/acschemneu ro.0c00122

7. Netland J, Meyerholz DK, Moore S et al (2008) Severe acute respiratory syndrome coronavirus infection causes neuronal death in the absence of encephalitis in mice transgenic for human ACE2. J Virol 82:7264-7275. https://doi.org/10.1128/JVI.00737-08

8. Piva S, Fagoni N, Latronico N (2019) Intensive care unitacquired weakness: unanswered questions and targets for future research. F1000Research. https://doi.org/10.12688/f1000resea rch.17376.1(eCollection 2019)

9. Medical Research Council (1981) Aids to the examination of the peripheral nervous system. Memorandum no. 45. Her Majesty's Stationery Office, London. https://mrc.ukri.org/research/facilities -and-resources-for-researchers/mrc-scales/mrc-muscle-scale/

10. Hough CL, Lieu BK, Caldwell ES (2011) Manual muscle strength testing of critically ill patients: feasibility and interobserver agreement. Crit Care 15:R43. https://doi.org/10.1186/cc10005

11. Stålberg E, van Dijk H, Falck B et al (2019) Standards for quantification of EMG and neurography. Clin Neurophysiol 130:16881729. https://doi.org/10.1016/j.clinph.2019.05.008

12. Latronico N, Bolton CF (2011) Critical illness polyneuropathy and myopathy: a major cause of muscle weakness and paralysis. 
Lancet Neurol 10:931-941. https://doi.org/10.1016/S1474 $-4422(11) 70178-8$

13. Van Aerde N, Meersseman P, Debaveye Y et al (2020) Five-year impact of ICU-acquired neuromuscular complications: a prospective, observational study. Intensive Care Med. https://doi. org/10.1007/s00134-020-05927-5(Epub ahead of print)

14. Kelmenson DA, Held N, Allen RR et al (2017) Outcomes of ICU patients with a discharge diagnosis of critical illness polyneuromyopathy: a propensity-matched analysis. Crit Care Med 45:2055-2060. https://doi.org/10.1097/CCM.0000000000 002763

15. Schaller SJ, Anstey M, Blobner M et al (2016) International early SOMS-guided mobilization research initiative. Early, goaldirected mobilisation in the surgical intensive care unit: a randomised controlled trial. Lancet 388(10052):1377-1388. https:// doi.org/10.1016/S0140-6736(16)31637-3 